4-19-2021

\title{
Musings on Patient Willingness to Pay
}

Dennis J. Baumgardner

Follow this and additional works at: https://aah.org/jpcrr

Part of the Analytical, Diagnostic and Therapeutic Techniques and Equipment Commons, Community Health and Preventive Medicine Commons, Health Services Research Commons, and the Primary Care Commons

\section{Recommended Citation}

Baumgardner DJ. Musings on patient willingness to pay. J Patient Cent Res Rev. 2021;8:83-5. doi: 10.17294/2330-0698.1851

Published quarterly by Midwest-based health system Advocate Aurora Health and indexed in PubMed Central, the Journal of Patient-Centered Research and Reviews (JPCRR) is an open access, peer-reviewed medical journal focused on disseminating scholarly works devoted to improving patient-centered care practices, health outcomes, and the patient experience. 


\title{
Musings on Patient Willingness to Pay
}

\author{
Dennis J. Baumgardner, MD | Editor-in-Chief \\ Department of Family Medicine, Aurora UW Medical Group, Advocate Aurora Health, Milwaukee, WI
}

$\mathrm{I}$ $\mathrm{n}$ this issue of the Journal of Patient-Centered Research and Reviews (JPCRR), an article by Floyd and colleagues (see p. 98) describes patient-reported willingness to pay (WTP) for treatment to restore their chronically diseased knee to ideal function. ${ }^{1}$ The mean U.S. dollar amount for patients from a single orthopedic practice in South Carolina, as measured in 2018, was $\$ 18,704$. The total WTP amount generally increased with higher income category, as anticipated. Subjects reported a mean WTP of \$291 for each 1-unit improvement on a 100-point percentage of normal scale regarding their knee. ${ }^{1}$

My fascination with measurements such as WTP prompted a distinctly nonsystematic sampling of WTP literature from developed countries to see what I could glean. Intuitively, WTP should vary with patient perception of their symptoms or disability, the value they place on them, their level of total or disposable income, cultural and demographic factors, competing priorities, and personal philosophy. Indeed, most of these assumptions are borne out. ${ }^{2-8}$ Interestingly, WTP does not appear to correlate with quality-adjusted lifeyear measurements, at least in some studies. ${ }^{9,10}$ Adjusting for exchange rate when necessary, ${ }^{11}$ and for inflation from the time period in each study to 2018 U.S. dollars, ${ }^{12}$ I calculated hypothetical WTP (out of pocket) from a sample of 13 survey-format studies for a variety of medical procedures or cures.

\section{Conditions, Treatments}

Continuing with the subject tackled by Floyd et al, namely relief for symptoms of knee osteoarthritis, a 2012 study of 2073 subjects in 5 European countries found WTP of $\$ 49$ per course of corticosteroid joint injections and $\$ 89$ per course of viscosupplement injections. ${ }^{6}$ WTP amount correlated with level of disposable income. An earlier study from Texas found race/ethnicity differences, which explained $21 \%-30 \%$ of the variation in log WTP for improvement in arthritic knee symptoms. ${ }^{2}$ This study reported that White (non-Hispanic), Hispanic, and African

Corresponding author: Dennis J. Baumgardner, MD, Aurora Sinai Medical Center, 1020 N. 12th Street, \#4180, Milwaukee, WI 53233 (dennis.baumgardner@aah.org)
American subjects expressed WTP at $52 \%, 37 \%$, and $28 \%$ of their mean income values, respectively, for relief of severe osteoarthritis. This compares to $4.5 \%, 7.1 \%$, and $25.5 \%$, respectively, of mean income for a week's vacation, and $3.1 \%, 3.7 \%$, and $10.0 \%$, respectively, to have their house painted. Once individual characteristics

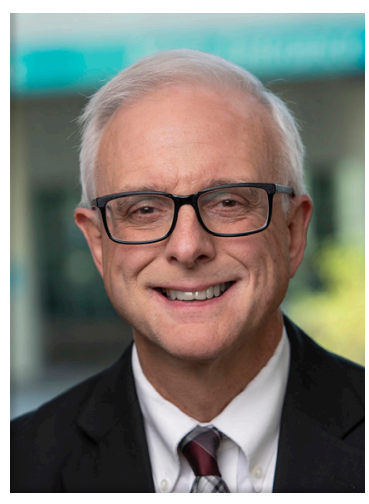
and income were controlled for, there were no statistical differences in WTP between the 3 race/ethnicity groups for nonhealth expenditures. Controlling for income differences between groups, log WTP remained significantly different for White vs African American subjects but not for White vs Hispanic subjects. ${ }^{2}$

A study of 40 psoriasis patients in Massachusetts (45\% with income of $\leq \$ 54,500)$ found mean WTP for hypothetical cure to be $\$ 2422$ for physical and emotional relief and \$757 for ability to sleep. ${ }^{13}$ A 2008 study of 197 members of an Australian self-help group had an average WTP of $\$ 5540$ (including 20\% who expressed a WTP as high as $\$ 29,157$ ) for complete resolution of tinnitus. ${ }^{14}$

Gan and colleagues studied WTP regarding intraand postoperative complications of subjects in North Carolina. $^{3,15}$ Median WTP for a monitor to avoid intraoperative awareness among 60 individuals was $\$ 47$, given a baseline incidence of 5 out of 1000 cases. $^{15}$ Median WTP for a completely effective postoperative antiemetic was $\$ 82$ (\$146 if vomiting had been experienced in a previous postoperative state). ${ }^{3}$ In the 80 -subject study population, WTP increased for those with higher income, with history of postoperative nausea or vomiting, who placed more individual importance on those symptoms, and who were married. ${ }^{3}$

\section{Screenings and Tests}

Regarding screening tests and medical decision-making, a multisite national study found WTP for a web-based decision support system among 248 men with newly diagnosed localized prostate cancer was $\$ 27$ above usual care. ${ }^{7}$ WTP was significantly associated with income, 
marital status, stage of decision-making, and starting "bid" in the iterative bidding survey. A study of WTP for predictive tests without immediate treatment implications among 2223 U.S. adults ranged from $\$ 126$ to $\$ 304 .{ }^{8} \mathrm{WTP}$ varied with income, the particular disease, whether the test was "perfect" or "imperfect," and study-measured risk-taking behavior (lower risk-taking individuals were less likely to want a test).

A 2012 vignette-based study of 3469 patients in the United Kingdom (64\% with annual income of $\leq \$ 42,650)$ regarding cancer screening in primary care revealed WTP amounts of $\$ 643$ for colorectal, $\$ 584$ for lung (chest $\mathrm{X}$-ray), and $\$ 638$ for pancreatic screening. ${ }^{16}$ Only lung screening showed a variation in WTP according to pretest probability.

\section{Chronic Disease}

Hypothetical WTP for a subject treatment visit (if not provided at no cost) as part of a patient-centered blood pressure control research study set in southeastern Michigan was found to be $\$ 27$ in a pilot of 38 subjects. ${ }^{17}$ Massachusetts parents of 638 children 2-12 years of age were queried regarding WTP for continuing in a pediatric weight management program. ${ }^{5}$ A minority $(31 \%)$ of parents indicated WTP to receive enhanced primary care for this purpose and would pay a median of $\$ 21$ per month; 45\% had WTP for enhanced primary care plus individual coaching (median WTP of \$29 per month).

Tangential to the relative dearth of articles on WTP for programs aimed at helping control chronic medical problems in the United States are a pair of European studies. After having attended an educational program, 202 German patients expressed WTP of \$23-\$61 per month to attend a primary care-based health educational program (no correlation with income). ${ }^{18}$ Internet questionnaire results from 461 Swedish patients with type 2 diabetes revealed a WTP of $\$ 25$ per month to lose $1 \mathrm{~kg}$ of weight, $\$ 60$ per month to decrease hypoglycemic episodes from 3 to 1 per month, and $\$ 81$ per month to avoid nausea completely. ${ }^{19}$

I have known patients with disabling, severely painful arthritis and unrelenting tinnitus, thus the relatively high WTP in these subject populations is not surprising. ${ }^{1,2,14}$ It would certainly be hard for me personally to put a price on relief of some acute symptoms. All debate about third-party payment aside, as a primary care physician, I was struck by the apparent lower WTP for treatment of chronic diseases., ${ }^{517-19}$ I have always struggled to know how to push the asymptomatic or minimally symptomatic potential killers (hypertension, chronic kidney disease, etc) higher up a patient's priority list.
In Charles Dickens' A Christmas Carol, Ebenezer Scrooge changes his miserly attitude only after three ghosts show him the error of his ways. I sometimes wonder if a visit from "the ghost of chronic disease future" would impact patients more than any clinical words of wisdom. As for the here and now, how do we adequately educate our patients regarding risk of lifechanging events?

Submissions to JPCRR addressing effective patient education on the value of chronic disease management would be most welcome.

\section{References}

1. Floyd SB, Oostdyk A, Cozad M, Brooks JM, Siffri P, Burnikel B. Assessing the patient-perceived monetary value of patientreported outcome improvement for patients with chronic knee conditions. J Patient Cent Res Rev. 2021;8:98-106.

2. Byrne MM, O'Malley KJ, Suarez-Almazor M. Ethnic differences in health preferences: analysis using willingnessto-pay. J Rheumatol. 2004;31:1811-8.

3. Gan TJ, Sloan F, de L Dear G, El-Moalem HE, Lubarsky DA. How much are patients willing to pay to avoid postoperative nausea and vomiting? Anesth Analg. 2001:92:393-400. CrossRef

4. Singer E, Couper MP, Fagerlin A, et al. The role of perceived benefits and costs in patients' medical decisions. Health Expect. 2014;17:4-14. CrossRef

5. Drouin O, Sharifi M, Gerber M, et al. Parents' willingness to pay for pediatric weight management programs. Acad Pediatr. 2019;19:764-72. CrossRef

6. Posnett J, Dixit S, Oppenheimer B, Kili S, Mehin N. Patient preference and willingness to pay for knee osteoarthritis treatments. Patient Prefer Adherence. 2015;9:733-44. CrossRef

7. Wilson LS, Blonquist TM, Hong F, et al. Assigning value to preparation for prostate cancer decision making: a willingness to pay analysis. BMC Med Inform Decis Mak. 2019;19(1):6. CrossRef

8. Neumann PJ, Cohen JT, Hammitt, et al. Willingness-to-pay for predictive tests with no immediate treatment implications: a survey of US residents. Health Econ. 2012;21:238-51. CrossRef

9. Bala MV, Wood LL, Zarkin GA, Norton EC, Gafni A, O'Brien B. Valuing outcomes in health care: a comparison of willingness to pay and quality-adjusted life-years. J Clin Epidemiol. 1998;51:667-76. CrossRef

10. Franic DM, Pathak DS, Gafni A. Quality-adjusted life years was a poor predictor of women's willingness to pay in acute and chronic conditions: results of a survey. J Clin Epidemiol. 2005;58:291-303. CrossRef

11. Pound Sterling Live. Accessed February 4, 2021. www. poundsterlinglive.com

12. US Inflation Calculator. Inflation calculator. Accessed February 4, 2021. www.usinflationcalculator.com

13. Delfino M Jr, Holt EW, Taylor CR, Wittenberg E, Qureshi AA. Willingness-to-pay stated preferences for 8 health-related quality-of-life domains in psoriasis: a pilot study. $\mathrm{J} \mathrm{Am} \mathrm{Acad}$ Dermatol. 2008;59:439-47. CrossRef

14. Tyler RS. Patient preferences and willingness to pay for tinnitus treatments. $J$ Am Acad Audiol. 2012;23:115-25. 
15. Gan TJ, Ing RJ, de L Dear G, Wright D, El-Moalem HE, Lubarsky DA. How much are patients willing to pay to avoid intraoperative awareness? J Clin Anesth. 2003;15:108-12. CrossRef

16. Hollinghurst S, Banks J, Bigwood L, Walter FM, Hamilton $\mathrm{W}$, Peters TJ. Using willingness-to-pay to establish patient preferences for cancer testing in primary care. BMC Med Inform Decis Mak. 2016;16:105. CrossRef

17. Gleason-Comstock J, Streater A, Goodman A, et al. Willingness to pay and willingness to accept in a patientcentered blood pressure control study. BMC Health Serv Res. 2017;17(1):538. CrossRef
18. Wiesemann A, Mueller-Buehl U, Scheidt R, Boehme W, Scheuermann W. Patient willingness to pay for preventive measures in primary care: a study of five GPs in a German community. Soz Praventiymed. 2004;49:254-60. CrossRef

19. Jendle J, Torffvit O, Ridderstrále, Lammert M, Ericsson A, Bøgelund M. Willingness to pay for health improvements associated with anti-diabetes treatments for people with type 2 diabetes. Curr Med Res Opin. 2010;26:917-23. CrossRef

(C) 2021 Advocate Aurora Health, Inc. 